\title{
Myiasis gastrointestinal humana por Eristalis tenax*
}

\section{G astrointestinal human myiasis for Eristalis tenax}

\section{Marcelo Kun, Ana Kreiter y Liliana Semenas}

Laboratorio de Parasitología del Centro Regional Bariloche de la Universidad Nacional del Comahue. Bariloche, Argentina

KU N Marcelo, Ana Kreiter y Liliana Semenas, Myiasis gastrointestinal humana por Eristalis tenax* Rev. Saúde Pública, 32 (4): 367-9, 1998 


\title{
Myiasis gastrointestinal humana por Eristalis tenax*
}

\author{
G astrointestinal human myiasis for Eristalis tenax
}

\author{
Marcelo Kun, Ana Kreiter y Liliana Semenas \\ Laboratorio de Parasitología del Centro Regional Bariloche de la Universidad Nacional del \\ Comahue. Bariloche, Argentina
}

\begin{abstract}
Resumen
Son caracterizadas las myiasis registradas en Bariloche y establecidas las condiciones probables bajo las cuales se produjeron las infestaciones. Las larvas obtenidas a partir de heces de 2 pacientes fueron identificadas como Eristalis tenax (Diptera: Syrphidae) de acuerdo a las claves de Hartley (1961) y Organización Panamericana de la Salud (1962). Estos 2 casos de myiasis gastrointestinal humana constituyen los primeros registrados en Bariloche (Patagonia, Argentina) y sus características responden a las registradas para esta especie de Díptera en otras partes del mundo. La falta de control específico en el sistema domiciliario de suministro de agua ha sido la causa más probable de la infestación. Este registro extiende la distribución de E. tenax y de las myiasis gastrointestinales humanas en América del Sur hasta los $41^{\circ} 03^{\prime} \mathrm{S}$.
\end{abstract}

Miiasis. Consumo domestico de água. Eristalis tenax.

\begin{abstract}
The myiasis observed in Bariloche are characterized and the probable conditions under which the infestations took place established. The larvae obtained from faeces of 2 patients were identified as Eristalis tenax (Diptera: Syrphidae) according to Hartley (1961) and Organización Panamericana de la Salud keys (1962). These 2 cases of human gastrointestinal myiasis were the first to be registered in Bariloche (Patagonia, Argentina) and their characteristics were similar to those described for this species in other parts of the world. The lack of specific control measures in the domestic water supply system was the most probable cause of the infestation. This event extends the distribution of $\mathrm{E}$. tenax and human gastrointestinal myiasis in South America to $41^{\circ} 03^{\prime} S$.
\end{abstract}

Myiasis. Domestic water consumption. E ristalis tenax.

*Apoio financiero: Secretaría de Investigación de la Universidad Nacional del Comahue. Presentado en la III Reunión Científica sobre Parasitismo en Ecosistemas de Agua Dulce, Valdivia, Chile, 1996.

Correspondencia para/Correspondence to: Liliana Semenas - Unidad Postal Universidad. 8400, Bariloche, Argentina.

E-mail: 1semenas@uncmai.edu.ar

Recibido en 10.11.1997. Reapresentado en 29.3.1998. Aprobado en 22.4.1998. 


\begin{abstract}
Resumo
Foram caracterizadas as miasis registradas em Bariloche (Patagonia, Argentina) e estabelecidas as prováveis condições sob as quais são produzidas as infestações. As larvas obtidas a partir das fezes de dois pacientes foram identificadas como Eristalis tenax (Diptera: Syrphdae). Esses dois casos de miasis gastrointestinal humana foram os primeiros registrados em Bariloche, Argentina, e suas características respondem às registradas para esta espécie de Diptera em outras partes do mundo. A falta de controle específico no sistema domiciliário de abastecimento de água tem sido a causa mais provável de infestação. Este registro amplia a distribuição de E. tenax e das miasis gastrointestinais humanas em América do Sul até os $41^{\circ} 03$ 's.
\end{abstract}

Miasis. Consumo doméstico de água Eristalis tenax.

Las myiasis gastrointestinales son infestaciones accidentales provocadas por la ingestión de comida o líquidos contaminados con larvas o huevos de mosca $^{4,9}$ que se desarrollan en estómago, intestino o recto ${ }^{3,5,7}$. Los casos registrados en el mundo corresponden a los géneros: Fannia, Musca, Muscina, Stomoxys (Muscidae); Sarcophaga, Parasarcophaga (Sarcophagidae); Piophilla (Piophillidae); Calliphora, Callitroga, Lucilia (Calliphoridae); Eristalis, Helophilus (Syrphidae); Megaselia (Phoridae); Calobata (Tylidae); Psychoda (Psychodidae); Drosophila (Drosophilidae) y Oestrus (Oestridae) $^{3,4,5,9,11}$. En Argentina, el primer caso de myiasis se registró en 1941 y fue provocado por Eristalis tenax ${ }^{l}$. Actualmente las myiasis registradas incluyen infestaciones por Sarcophaga sp., Piophilla casei, Callitroga macellaria y Oestrus ovis ${ }^{2,3,5}$.

El objetivo del presente trabajo es caracterizar las myiasis registradas en Bariloche y establecer las condiciones probables bajo las cuales se produjeron.

Las larvas, extraídas de las heces de 2 pacientes, se conservaron en alcohol $70 \%$ y se identificaron con las claves de OPS $^{9}$ y de Hartley ${ }^{6}$. Los ejemplares se depositaron en la Colección de Referencia del Laboratorio de Parasitología CRUB - UNC(N ${ }^{\circ}$ F 78/1). Información adicional sobre ambos casos se obtuvo por datos proporcionados por los pacientes y los médicos.

El material corresponde a tercer estadio larval de Eristalis tenax (Diptera: Syrphidae) (Fig.) El registro conocido de este díptero en América llegaba hasta los 40 $10^{\circ} \mathrm{S}$; $71^{\circ} 33^{\prime} \mathrm{W}$ (San Martín de los Andes, Neuquén $)^{12}$ por lo tanto su presencia en Bariloche extiende su distribución hasta los $41^{\circ} 03^{\prime} \mathrm{S} ; 7^{\circ} 25^{\prime}$, W. Constituye el primer registro de myiasis gastrointestinal para Bariloche y el más austral por

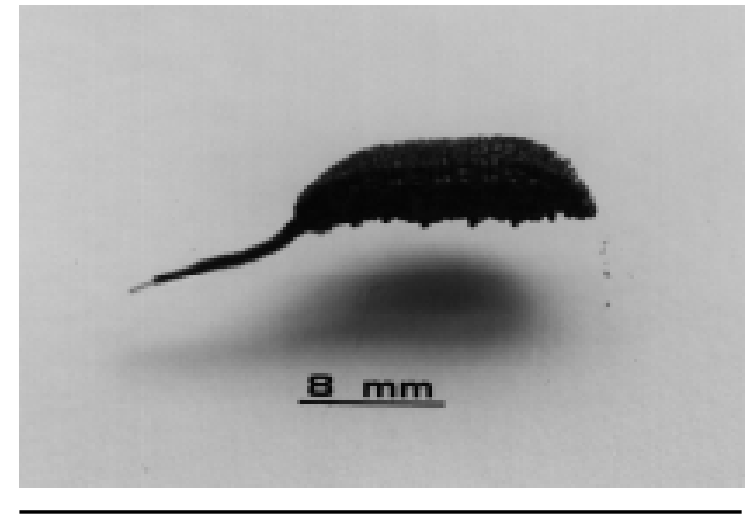

Figura- Larva de Eristalis tenax recuperada de heces humanas.

esta especie para la Argentina. En Macao una investigación realizada entre enero de 1987 y agosto de 1989, solamente registró 6 casos de myiasis gastrointestinal sobre 1.889 pacientes examinados ${ }^{4}$, al igual que en la Argentina donde los registros de estas myiasis son poco frecuentes.

Ambas infestaciones fueron de carácter múltiple, por ello se suministró a los pacientes purgante para asegurar la eliminación completa de las larvas y un antibiótico como medida de prevención. Las características de los pacientes (mujer de 25 años; varón de 15 años) indican que la edad y el sexo en las infestaciones es variado, al igual que lo registrado a nivel mundil ${ }^{1,2,4,11}$. Los síntomas de las myiasis son inespecíficos y pueden confundirse con otros disturbios del tubo digestivo ocasionados por virosis, bacteriosis o intoxicaciones ${ }^{8}$. Sus aspectos clínicos varían de acuerdo al número de huevos o larvas tragadas, al órgano afectado y a la especie de mosca involucrada ${ }^{8}$. En general, los pacientes concurren a 
consulta por haber eliminado en forma espontánea las larvas o por malestares persistentes en el tubo digestivo. En los presentes casos de myiasis, corresponden uno a infestación estomacal (varón) caracterizada por náuseas, dolor epigástrico y vómitos y el otro a infestación intestinal con eliminación espontánea, diarrea y cólicos (mujer).

El aprovisionamiento de agua, la eliminación de residuos, el nivel socioeconómico de los pacientes y el hábito de la especie de díptero son las variables que deben considerarse para una evaluación epidemiológica en infestaciones por larvas de moscas ${ }^{9}$. Sin embargo, la ingestión de agua contaminada con huevos o larvas se considera la fuente principal de infestaciones por E. tenax ${ }^{3}$. En Bariloche, el agua domiciliaria se obtiene desde vertientes ubicadas en los cerros aledaños a la ciudad o desde el lago Nahuel Huapi, se acumula en tanques cerrados y se somete a chequeos para detectar la presencia de bacterias coliformes. Ambos pacientes tienen buen nivel socioeconómico, son residentes permanentes en la zona, viven en el mismo barrio, están conectados a la red de distribución domiciliaria de agua y han adquirido la infestación a fines del verano en años sucesivos (1995 y 1996). Esto indicaría que la causa más probable de la infestación ha sido la contaminación del agua de consumo.

Sería conveniente establecer un sistema de control sobre la presencia de larvas y huevos en los tanques de almacenaje de agua, dado que las hembras adultas de E. tenax oviponen en aguas servidas o estancadas con tenor de oxígeno escaso o nulo ${ }^{8}$ y la larva se alimenta de bacterias, materia orgánica y hojarasca ${ }^{12}$. La demografía de esta especie, sinántropa, cosmopolita y considerada de importancia sanitaria menor por la Organización Panamericana de la Salud ${ }^{7,9,12}$, no puede ser controlada mientras haya comida y refugio generados por las actividades humanas y condiciones de temperatura que faciliten la presencia de habitats adecuados para la supervivencia de las larvas ${ }^{9,10}$, convirtiéndose así en una especie indicadora de la calidad sanitaria de los ambientes ${ }^{12}$.

\section{REFEREN CIAS}

1. BACIGALUPO, J.; PEREZ VUIDEPOT, C.; DIDIEGO, E.P. Primera observación argentina de miasis intestinal por Eristalis tenax L. Semana Méd., 48: 555-6, 1941.

2. BACIGALUPO, J. \& VILLAMIL, C.F. Miasis humana por Oestrus ovis Linneo, 1761. In: Jornadas Entomoepidemiológicas Argentinas, I, Buenos Aires, 1959. p.833-6.

3. DEL PONTE, E. Manual de entomología médica y veterinaria argentinas. Buenos Aires, Ediciones Librería del Colegio, 1958.

4. FERREIRA, M.F.; IENG, K.K.; CLARO, L.; GAR-WAI, C.; SHINONAGA, S.; GOTO, T. Intestinal myiasis in Macao. Chin. J. Parasitol. Parasit. Dis., 8: 214-7, 1990.

5. GREENWAY, D.F. Zooparásitos y zooparasitosis humanas. Buenos Aires, Editor Aniceto López, 1939.

6. HARTLEY, J. C. A taxonomic account of the larvae of British Syrphidae. Proc. Zool. Soc. London, 136 : 505-73, 1961.
7. JAMES, M. The flies that cause myiasis in man. United States Department of Agriculture, 1947. (Misc. Publ. No 631).

8. MARKELL, E.K.; VOGE, M.; JOHN, D.T.Medical parasitology. 6th. ed. Philadelphia, W.B. Saunders Co., 1986.

9. ORGANIZACION PANAMERICANA DE LA SALUD. Moscas de importancia para la salud pública y su control. Washington, 1962. (Publ. Cient. 61).

10. ROBINSON, W. H. Urban entomology: insect and mite pests in the human environment. London, Chapman \& Hall, 1996.

11. SHIOTA, T.; YOSHIDA, Y.; HIRAI, S.; TORII, S. Intestinal myiasis caused by Parasarcophaga crassipalpis (Diptera: Sarcophagidae). Pediatrics, 58: 215-7, 1990.

12. THOMPSON, F. C. Revision of the Eristalis flower flies (Diptera: Syrphidae) of the Americas south of the United States. Proc. Entomol. Soc. Wash., 99: 209-37, 1997. 